\title{
SIGNIFICADO PSICOLÓGICO DA DOR PARA ENFERMEIRAS E MEDICOS
}

\author{
* Wanda de Aguiar Horta \\ ** Silvia T. Maurer Lane \\ *** Elisabeth M. Cnandelier \\ *** Denise A. da Costa \\ *** Ruth Castro
}

RBEn/11

HORTA, W.A. e colaboradores - Significado psicológico da dor para enfermeiros e médicos. Rev. Bras. Enf.; DF, 29 : 96-99, 1976.

\section{NNTRODUÇA}

Prosseguindo nos estudos do comportamento verbal de profissionais da área de saúde em relação à dor, procuramos estudar, neste trabalho qual o significado psicológico da dor para enfermeiros e médicos de uma instituição hospitalar.

Considera-se "significado psicológico" uma característica do comportamento verbal, resultante das contingências sociais às quais o indivíduo está sujeito, pode-se pressupor que numa instituição, enquanto comunidade, existam condiçōes que controlarão comportamento verbais dos individuos bem como diferenças entre grupos variáveis conforme variem aquelas contingências.
O trabalho pretende verificar se 0 comportamento verbal de um grupo de enfermeiros é semelhante daquele apresentado por um grupo de médicos dentro da mesma instituição, portanto sujeitos às mesmas contingências sociais.

\section{HIPOTESE}

Os enfermeiros, quanto ao significado psicológico da dor, diferem significativamente dos médicos nas dimensōes: valorativa, potência e atividade da Escala do Diferencial Semântico de Osgood.

\section{METODOLOGIA}

População - Constituída de 33 enferfermeiros (quatro do sexo masculino e

- Professor Adjunto da EEUSP.

* Professor D.outor Associado da Faculdade de Psicologia da Pontifícia Universidade Católica de São Paulo.

** Alunas da Escola de Enfermagem da USP. 
HORTA, W.A. e colaboradores - Significado psicológico da dor para enfermelros e médicos. Rev. Bras. Enf.; DF, 29 : 96-89, 1976.

29 do sexo feminino) e 33 médicos (seis do sexo feminino e 27 do sexo masculino). A população estudada situou-se no grupo etário de 20 a 50 anos, sendo todos brasileiros e trabalhando na mesma instituição hospitalar.

Instrumento - $\mathrm{O}$ instrumento utilizado para medir o significado psicológico foi o Diferencial Semântico, técnica desenvolvida por Osgood. Aplicou-se a forma reduzida para o Brasil, que irá constar do Atlas de 620 palavras para 30 comunidades lingüísticas.

Esta forma reduzida (Anexo 1), consta de 12 escalas com adjetivos bi-polares, dispostos ao acaso, e o valor final atribuído a cada dimensão é calculado pela soma algébrica dos valores decorrentes das respostas dadas às quatro escalas saturadas pelos fatores dimensionais. As dimensōes utilizadas neste trabalho são as básicas de Osgood: Valorativa, Potência e Atividade.

Aplicação do instrumento - Sua aplicação foi feita em pequenos grupos ou individualmente, precedida de prévia orientação e exercício para seu preenchimento. Chamou-se a atenção para que $o$ respondente não se demorasse na atribuição de valores, a fim de que se pudesse obter uma reação espontânea de cada um sobre o conceito dimensionado nas escalas.

\section{RESULTADOS}

Os dois grupos foram semelhantes, ambos consideraram a dor na dimensão: Valorativa - doentia, horrível, indesejável e má; Potência - grande, pesada, alta e intensa; Atividade - mortal, barulhenta, rápida e ativa.

As diferenças encontradas entre os grupos foram analisadas estatisticamente pela teoria das pequenas amostras, Distribuição de "Student" $T$, e os resultados não foram significantes a nível de 0,$01 ; 0,05 ; 0,010$.
A polarização dos enfermeiros e médicos no fator I - Valorativo reflete-se respectivamente nas médias $-2,28$ e $-2,14$.

Quanto a contradição interna os médicos apresentaram os índices 0,$05 ; 0,27$; 0,17 respectivamente para o Fator I Valorativo, Fator II - Potência e Fator III - Atividade. Estes índices próximos de zero são indicativos de comportamentos verbais estereotipados, especialmente no Fator Valorativo.

Os enfermeiros, em seqüência dos mesmos fatores apresentaram os índices de $0,06,1,10$ e 0,35. Estes resultados diferiram dos médicos em relação ao fator II mostrando contradição interna na dimensão Potência, nos demais fatores os valores aproximaram-se de zero, em especial o valorativo indicando estereotipia.

\section{DISCUSSAOO}

A hipótese levantada foi rejeitada uma vez que os resultados obtidos indicaram o mesmo comportamento verbal tanto para os enfermeiros como para os médicos.

Em estudos anteriores realizados com profissionais de saúde, com docentes e estudantes de enfermagem e psicologia, os resultados encontrados foram semelhantes, embora tivéssemos utilizado como instrumento a Escala do Diferencial Semântico de Lane, que se compõe de 7 fatores, todos relacionados aos fatores básicos de Osgood. Estudos realizados com pacientes, com a escala de Lane, também confirmaram a estereotipia na dimensão Valorativa.

Em trabalho recente, ainda não publicado, Lane, utilizando como enstrumento a forma reduzida do Diferencial Semântico de Osgood em 40 sujeitos de 13 a 17 anos, do sexo masculino, verificou que o grupo do Brasil quando comparado com outros grupos da América Latina (México, Yucatan, Costa Rica), 
HORTA, W.A. e colaboradores - Significado psicológico da dor para enfermeiros e médicos. Rev. Bras. Enf.; DF, $29: 96-99,1976$.

desvalorizam menos a dor, com contradiçōes internas. $\mathrm{Na}$ análise de componentes os conceitos ódio e dor (desagradáveis) são mais ativos que amor e prazer (agradáveis).

Quais as contingências que levam enfermeiros e médicos a darem o mesmo significado psicológico para a dor? No fator Valorativo uma provável causa será o fator cultural, mas até que ponto este fator estaria influindo?

Teriam as escolas de enfermagem e de siedicina, enquanto instituiçōes, influido nestes resultados? $\mathbf{E}$ as contingências da instituição hospitalar, o contato diário com a dor sob todas as formas e manifestaçōes, também não atuariam no comportamento verbal destes profissionais? Chama a atenção o fato dos enfermeiros apresentarem contradição interna no fator II - Dimensão Potência, o que os leva a dividirem-se entre considerar a dor - grande, pesada, alta, Intensa - e pequena, leve, baixa e fraca.

Observa-se também a grande incoerência entre os conhecimentos científicos a respeito da dor, como importante sinal de alarme e defesa orgânica, enfatizado em aulas dadas a futuros profissionais, e o aparente fato destes conhecimentos não alterarem o significado psicológico da dor para aqueles mesmos profissionais.

Teriam eles respondido ao questionário como leigos ou como profissionais? Muitas indagaçōes poderiam ser feitas e motivos para outras pesquisas no gênero. Como agem realmente os profissionais estudados perante a dor de seus clientes? Eles a percebem obedecendo a um comportamento estereotipado, automático, ou tomam comportamentos deliberativos, individualizando cada cliente em seu atendimento?

CONCLUSAO - Médicos e enfermelros não diferem significantemente quanto ao significado psicológico da dor segundo a Escala reduzida do Diferencial Semântico de Osgood. Ambos consideram a dor doentia, horrível, indesejável, má, grande, pesada, alta, intensa, mortal barulhenta, rápida e ativa.

\section{BIBLIOGRAFIA}

1. HORTA, W. de Aguiar \& KANNEBLEY, Z. - O diferencial Semântico de Osgood na avaliação da dor pós-operatória. Ciência e Cultura, 26 (7): 537, Julho de 1974.

2. HORTA, W. de Aguiar \& KANDNBLEY, Z. - Avaliaçāo da dor em pacientes submetidos a cirurgia de tiróide pela aplicação do método da Escala Diferencial Semântica de Osgood. Rev. Bras. de Enf. XXVIII (2) : 4353, abril/Junho de 1975.

3. HORTA, W. de Aguiar. - Dor: seu significado psicológico para estudantes e docentes de enfermagem e psicologia. Enf. Novas Dimens. 2 (1): 1-4, março/abril de 1976.

4. LANE, Silvia, Maurer - Significado Psicológico de palavras em diferentes grupos sócio-culturais. Tese de Doutoramento. Revista de Psicologia Normal e Patológica, XVIII (3-4): 3-152, Julho/dezembro de 1972.

5. OSGOOD, Charles E. - Exploration in Semantic Space: a Personal Diary. Journal of Social Issues, 27 (4) : 5-64, 1971. 
HORTA, W.A. e colaboradores - Significado psicológico da dor para enfermeiros e médicos. Rev. Bras. Enf.; DF, 29 : 96-99, 1976.

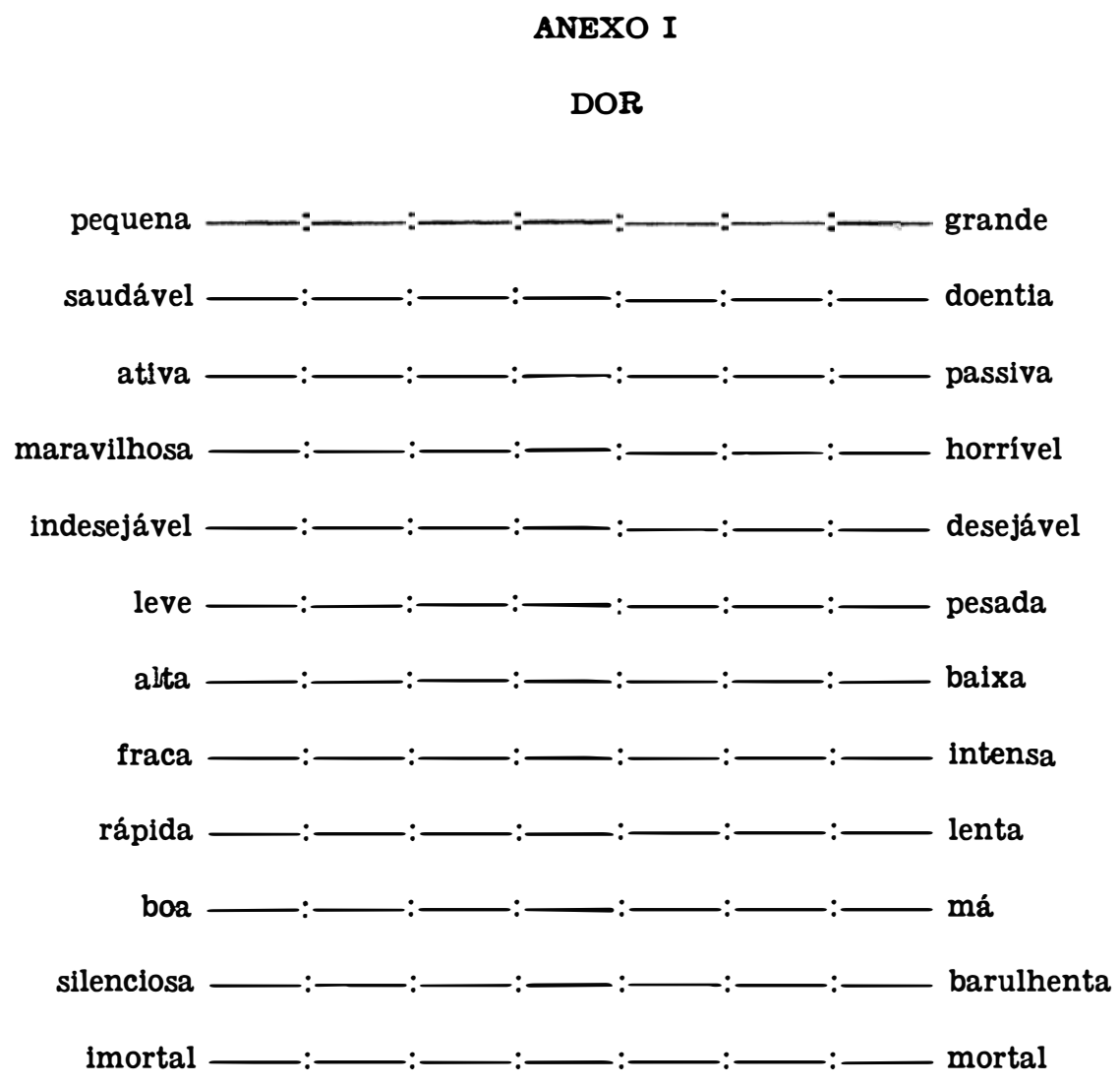

